\title{
OS DIREITOS SOCIAIS E A CONCILIAÇÃO COMO MECANISMO DE RESOLUÇÃO DE CONFLITOS
}

\author{
SOCIAL RIGHTS AND CONCILIATION AS A CONFLICT RESOLUTION MECHANISM
}

\section{Cristiane de Lima Geist ${ }^{1}$}

\section{RESUMO:}

O presente artigo versa sobre os direitos sociais e a conciliação como mecanismo para enfrentar a crise produzida pelo excesso de judicialização do Estado de Bem-Estar Social. A conciliação visa imprimir celeridade na solução dos conflitos, diminuição de custos e desgastes. Por meio do método de abordagem hipotético-dedutivo e do método de procedimento histórico, monográfico e dissertativo, com a utilização de pesquisas bibliográficas, a investigação percorreu os seguintes caminhos: partiu do estudo do surgimento dos direitos sociais, as dificuldades do Estado na implementação de tais direitos. Posteriormente dando especial enfoque a conciliação tomada como mecanismo redutor de custos e desgastes entre as relações sociais e estatais, semeadora da cultura da paz e incentivadora do exercício da cidadania. Busca-se, assim, indicar um possível patamar superior das relações entre os privados, produzido a partir do exemplo do Estado na relação com a sociedade, encurtando o caminho de acesso aos direitos, diminuindo gastos públicos e privados, fomentando o exercício democrático da cidadania e a cultura da paz, tudo no intuito de dar eficácia aos objetivos do Estado de Bem-Estar Social e evitar o risco das tentações populistas e/ou autoritárias, esse monstro nem tão adormecido a fustigar as sociedades em crise.

PALAVRAS-CHAVE: Conciliação. Direitos Sociais. Estado de Bem-Estar Social. Judicialização.

\begin{abstract}
:
This article deals with social rights and conciliation as a mechanism to deal with the crisis caused by the excessive judicialization of the Welfare State. The conciliation aims to print speed in the solution of conflicts, cost and wear reduction. Through the
\end{abstract}

\footnotetext{
${ }^{1}$ Doutorado e Mestrado em Direito da Universidade Regional Integrada do Alto Uruguai e das Missões (URI), Campus Santo Ângelo (2018). Especialista em Docência na Educação Profissional, Técnica e Tecnológica pelo Instituto Federal de Educação, Ciência e Tecnologia Farroupilha (2013). Graduada em Direito pelo Instituto Cenecista de Ensino Superior de Santo Ângelo - IESA (2005). Membro do Grupo de Pesquisa registrado no CNPq: Direitos de Minorias, Movimentos Sociais e Políticas Públicas. E-mail: cristianegeist@gmail.com ORCID https://orcid.org/0000-0003-4975-8384
} 
hypothetical-deductive approach and the method of historical procedure, monographic and dissertative, with the use of bibliographical research, the study went through the following sequence: it started from the study of the emergence of social rights and the difficulties of the State in the implementation of such rights. Subsequently it focused on conciliation, understood as a mechanism for reducing costs and wear between social and state relations, seeding of the culture of peace and incentive of the exercise of citizenship. It pursued, therefore, to indicate a possible higher level of the relations between the private parties, produced from the example of the relation between the State and the society, shortening the way of access to the law, reducing public and private partnerships, promoting the democratic exercise of citizenship and the culture of peace. All of this in order to give effect to the objectives of the welfare state and to avoid the risk of populist and/or authoritarian temptations, a monster not so asleep that fustigates societies in crisis.

KEYWORDS: Conciliation. Social rights. Welfare State. Judicialization.

\section{CONSIDERAÇÕES INICIAIS}

O Brasil instituiu amplos direitos sociais em um período de crise do welfare state no plano internacional, enquanto que nos países desenvolvidos essa política foi estabelecida nos anos dourados do capitalismo. No período de 1970 e 1980, houve uma superprodução, ocasionando acúmulo de capital, de modo que o Estado, garantidor da ordem e da propriedade, aumentou suas funções, inclusive controlando as condições da força de trabalho. $O$ crescimento da população acaba por produzir o esgotamento de suas funções e dos seus objetivos.

Em solo pátrio, nos anos 80 ocorreu o processo constituinte, com ampla participação popular, coordenada por partidos, entidades de classe, sindicatos, entre outros, quando então foram inseridos na Constituição vários direitos sociais, entre eles a seguridade social, desdobrada nas áreas da saúde, previdência e assistência social. Cuida-se de um produto do exercício ativo da população, da cidadania participativa.

No entanto, o Estado mediante dificuldades e falta de planejamento tem sérias dificuldades para implementar os direitos sociais. Consequência disso é a judicialização das relações sociais e do Estado de Bem-Estar Social, uma vez que o cidadão não obtendo seu direito, acaba levando sua reivindicação até o Poder Judiciário para que este lhe conceda o benefício. Dessa forma, muitas ações estão se acumulando no judiciário, dificultando ainda mais o Estado no atendimento das demandas. 
Diante dessa preocupante realidade questiona-se qual poderia ser o mecanismo que proporcionaria melhores condições de o Estado de Bem-Estar Social cumprir com seu propósito. Assim, por meio do método de abordagem hipotético-dedutivo e do método de procedimento histórico, monográfico e dissertativo, a investigação percorreu o seguinte caminho: partiu do estudo do surgimento dos direitos sociais, das dificuldades do Estado na implementação de tais direitos, e em seguida verifica a conciliação como mecanismo redutor de custos e desgastes entre as relações sociais e estatais, semeadora da cultura da paz e incentivadora do exercício da cidadania.

A pesquisa, portanto, tem como objetivo analisar a conciliação, em especial no Juizado Especial Federal, o qual trabalha com demandas relacionadas com os direitos sociais, indicando um possível patamar superior das relações entre os privados, produzido a partir do exemplo do Estado na relação com a sociedade, encurtando o caminho de acesso aos direitos, diminuindo gastos públicos e privados, fomentando o exercício democrático da cidadania e a cultura da paz, tudo no intuito de dar eficácia aos objetivos do Estado de Bem-Estar Social.

\section{OS DIREITOS SOCIAIS}

O Brasil reconhece a seguridade social a partir dos anos 80 como dever do Estado, cujas ideias foram inspiradas nas experiências de welfare state da Europa. Entre os objetivos estava o de incluir as pessoas que se encontravam excluídas da proteção do Estado, e excluir ou amenizar as desigualdades entre os beneficiários rurais e urbanos, reconhecendo a seguridade como um direito de todos, além de ampliar a responsabilidade pública pelos riscos que a sociedade está submetida pelo processo de produção:

A Constituição de 1988 ampliou também, mais do que qualquer de suas antecedentes, os direitos sociais. Fixou em um salário-mínimo o limite inferior para as aposentadorias e pensões e ordenou o pagamento de pensão de um salário-mínimo a todos os deficientes físicos e a todos os maiores de 65 anos, independentemente de terem contribuído para a previdência. Introduziu ainda a licença-paternidade, que dá aos pais cinco dias de licença do trabalho por ocasião do nascimento dos filhos. [...] elevação da aposentadoria dos trabalhadores rurais para o piso de 
um salário-mínimo. Também foi positiva a introdução da renda mensal vitalícia para idosos e deficientes (CARVALHO, 2016, p. 208).

A Constituição de 1988 consolidou um patamar de proteção social mais abrangente, assegurando direitos sociais a toda a população, ideal inexistente no Brasil até aquele momento. A assistência social, por exemplo, foi entendida como política pública de proteção social que exigia a implementação de programas assistenciais, instaurando-se um novo padrão de proteção social. A Constituição Federal de 88, no art. 201, traz o sistema de previdência social, destacando que será organizado sob a forma de regime geral, de caráter contributivo e de filiação obrigatória, observados os critérios que preservem o equilíbrio financeiro e atuarial.

A partir dessa previsão, foram criadas as Leis $n^{0} 8.212$ e $n^{0}-8.213$, as quais descrevem a finalidade da Previdência Social: assegurar aos seus beneficiários meios indispensáveis de manutenção, por motivo de incapacidade, idade avançada, tempo de serviço, desemprego involuntário, encargos familiares e reclusão ou morte daqueles de quem dependiam economicamente. Quando o contribuinte incidir em algum dos casos previstos em lei e preencher os requisitos terá direito ao benefício da Previdência Social. Incumbe ao Instituto Nacional do Seguro Social (INSS) a execução das atividades políticas e operacionalização das diretrizes legais e constitucionais da Previdência Social. Portanto, a previdência social foi ampliada e o Estado tem alegado dificuldades econômico-financeiras para implementar plenamente os projetos constitucionais da área.

A área da saúde também experimentou um salto, com o Poder Público assumindo a responsabilidade pelo atendimento gratuito e universal do direito à saúde, sem qualquer necessidade de pagamento prévio pelo cidadão. No atual período histórico, isso não é tarefa fácil. Nesse sentido, Carvalho (2016, p. 225) entende que "os direitos sociais também são afetados. A exigência de reduzir o déficit fiscal tem levado governos de todos os países a reformas no sistema de seguridade social. Essa redução tem resultado sistematicamente em cortes de benefícios e na descaracterização do estado de bem-estar". Esta situação acaba gerando um excesso de demandas no Poder Judiciário. 


\section{AS DIFICULDADES DO ESTADO NA IMPLEMENTAÇÃO DOS DIREITOS SOCIAIS E A JUDICIALIZAÇÃO DO ESTADO DE BEM-ESTAR SOCIAL}

Com a complexidade das sociedades modernas, o Estado Liberal, o qual tinha como propósito o monopólio da jurisdição e a centralização do poder; enfraqueceu, e da mesma forma, o Estado Social não se mostrou eficiente para atender ao que se propôs:

Tanto na crise americana quanto na crise do euro, a solução encontrada foi, além da adoção de políticas econômicas recessivas, que geram o desemprego (problema social), o sacrifício dos direitos sociais. Quem paga a conta dos desmandos do capitalismo é o social. O elevado custo da salvação da economia mundial depois das manobras arriscadas dos operadores do sistema financeiro global, verdadeiro cassino, recaiu sobre o Estado de Bem-Estar Social. A conclusão revela-se de clareza solar: houve, de rigor, dupla punição ao Estado de Bem-Estar Social. Há uma espécie de circularidade neste processo. Primeiro, porque os recursos destinados ao social foram repassados ao sistema financeiro. Isso gerou déficit, aumento pesado das despesas públicas diretamente empenhadas na operação de salvação. Depois, porque a salvação, como se disse, encontra na recessão econômica o seu fundamento, o que gera desemprego. O desemprego, por sua vez, onera o Estado de Bem-Estar Social (VAZ, 2016, p. 86-87).

Essa realidade fez crescer o número de demandas judiciais, em especial quanto às questões previdenciárias, ampliando as demandas contra a Administração Pública, que passa a figurar entre os maiores litigantes, especialmente nos Juizados Especiais Federais:

A ineficácia do contencioso administrativo do INSS gera conflituosidade. O Poder Judiciário Federal, em especial o Juizado Especial Federal, vêse colonizado por ações judiciais de indivíduos que têm seus pedidos rechaçados na via administrativa. Há, por assim dizer, uma relativa substituição do INSS, entidade que tem a atribuição legal de conceder e manter os benefícios previdenciários, pelo Judiciário, que passa a ser, anomalamente, o locus de concessão desses benefícios, a última esperança dos que deles necessitam e preenchem os requisitos legais (VAZ, 2016, p. 282-283).

Tal fato vai de encontro aos anseios da sociedade, a qual encontra na litigiosidade uma barreira para a implementação de direitos: 
Afirmar que o Estado figura como o maior litigante da Justiça implica dizer que o Estado se coloca também como um obstáculo ao pleno exercício do direito de acesso à justiça, na medida em que ocupa todos os espaços do Poder Judiciário. Colonizando as estruturas da Justiça, o Estado culmina por congestionar suas vias de acesso, impedindo e retardando o normal trânsito de outras espécies de demandas e mesmo aquelas que contra si são direcionadas (VAZ, 2016, p. 229).

O fenômeno da judicialização do Estado de Bem-Estar Social é decorrente da concepção de que o Poder Judiciário, por meio do juiz, deve dizer quem tem ou não o direito, conforme destaca Berwanger (2015, p. 253), "assim, aprendeu-se ao longo da história que cabe ao Poder Judiciário julgar conflitos. É da essência do sistema do Direito buscar a solução ditada pelo Estado-Juiz. Julgar é o verbo a ser conjugado". No entanto, o Judiciário não consegue resolver todos os conflitos que chegam até ele, e o excesso de demandas acarreta uma sobrecarga, nesse sentido, observa Spengler (2010, p. 214), "é fato que o Judiciário viu sua estrutura (física, política, pessoal...) tornar-se inadequada diante dos avanços da sociedade moderna, sem o necessário acompanhamento em termos tecnológicos, administrativos e comportamentais".

Além disso, tem a morosidade pelo excesso de demandas, conforme lembram Stangherlin, Taborda e Gaglietti (2015, p. 153): "a chamada solução judicial, que se refere àquela imposta pelo Estado-juiz, por vezes deixa os jurisdicionados inconformados com a decisão, ao passo que demandam um tempo insustentável, não mais condizendo com as reais necessidades da sociedade hodierna".

Ao Estado foi determinada a função de pacificador social, no sentido de que, havendo cidadãos com direitos iguais, mas interesses opostos é ele que deve dizer o direito, impor uma solução à lide com base em normativos. Essa é a forma de jurisdição tradicional, que já não comporta as consequências da modernidade e da própria complexidade da sociedade. A crise do Poder Judiciário patrocinou a criação de meios de resolução de conflitos contemplando uma maior participação do cidadão:

Ao reconhecer que o sistema atual de representação política está em crise, devendo ser questionado e modificado radicalmente, torna-se imperiosa a superação desse quadro institucional através de fórmulas de organização mais democráticas e participativas, fundadas numa 
racionalidade diversa das atuais estruturas formais e burocratizadas. Trata-se da criação de novas institucionais políticos que contemplem novos sujeitos emergentes e que universalizem a prática da cidadania participativa, reconhecida pelo próprio texto constitucional brasileiro de 1988 (WOLKMER, 1999, p. 39).

Nesse momento, ocorre a passagem da ideia de que os conflitos apenas podem ser resolvidos mediante a intervenção judicial e, uma vez garantido, o sistema se torna eficiente, para o entendimento de que um sistema adequado é aquele que proporciona mecanismos para a prevenção e a resolução de divergências, fazendo ressurgir instrumentos consensuais de resolução de conflitos:

Neste quadro ampliado de transformações, readequações e repercussões, o sistema jurídico passa a privilegiar novas-antigas práticas de solução de controvérsias. O consenso emerge como o grande articulador destas novas práticas, podendo ser observado ocupando lugar em vários aspectos da ordem jurídica e promovendo a (re)introdução de práticas que, embora conhecidas, muitas delas, juridicamente, não tinham o reconhecimento/aceitação quotidiana dos operadores do Direito (MORAIS; SILVEIRA, 1999, p. 96-97).

Desde a Constituição de 1988, uma das pautas tem sido a necessidade de pensar em mecanismos de participação mais amplos, que oportunizem estruturar um sistema de proteção democrático e facilitado de gestão de conflitos, mediante a aproximação, a negociação, a agilidade, e a oralidade. Diante dessa nova concepção, a doutrina vem auxiliando na moldagem desses mecanismos de resolução de conflitos, além daqueles que se constituem pela intervenção do Juiz, como possibilidades de minimizar a crise do Poder Judiciário e do Estado:

O que não se pode esquecer é que nem a previsão de direitos sociais na Constituição, nem sua positivação na esfera infraconstitucional têm o condão de, por si só, produzir o padrão desejável de justiça social, já que fórmulas exclusivamente jurídicas não fornecem 0 suficiente instrumental para a sua concretização, assim como a efetiva implantação dos direitos sociais a prestações não pode ficar na dependência exclusiva dos órgãos judiciais, por mais que estes cumpram destacado papel nesta esfera (SARLET, 2015, p. 369).

Nesse sentido, busca-se visualizar outras possibilidades, novas formas de dar 
efetividade aos direitos sociais, não deixando apenas aos Poderes tal incumbência.

Realmente, como se pode corrigir o mundo público brasileiro mudando apenas as leis e a organização do Estado? Se não se faz simultaneamente uma série crítica da influência e do poder das redes de amizade e compadrio que ensopam toda a nossa vida política, institucional e jurídica? [...] No fundo, a proposta é somar as receitas do mundo público com o estudo crítico das relações pessoais. [...] Ao lado disso, seria necessário resgatar como uma dimensão altamente positiva, como patrimônio realmente invejável, toda essa nossa capacidade de sintetizar, relacionar e conciliar, criando áreas e valores ligados à alegria, ao futuro e à esperança. Num mundo que cada vez mais se desencanta consigo mesmo e institui um individualismo sem limites, que reduz os valores coletivos a mero apêndice da felicidade pessoal e do mercado, a capacidade de deslumbrar-se com a sociedade é algo muito importante e positivo. $E$ aqui, sem dúvida, podemos novamente sintetizar, de modo criativo e relacional, o indivíduo com as suas exigências e direitos fundamentais, com a sociedade, com a sua ordem, seus valores e necessidades (DAMATTA, 2004, p. 72-73).

Assim, é necessário estabelecer mecanismos em que não prevaleçam o individualismo e as questões de mercado, nem apenas o coletivismo, mas uma forma que agrega mecanismos sociais de convivência entre as pessoas, e entre essas e as Instituições, principalmente diante da falta de recursos que assola o país.

\section{O MECANISMO DA CONCILIAÇÃO}

Na conciliação, existe a figura de um terceiro que é uma espécie de intermediário entre os conflitantes, mas o poder de verificar e tratar seus conflitos está com as partes.

a conciliação é um instituto que tem por objetivo chegar voluntariamente a um acordo neutro e conta com a participação de um terceiro conciliador - que intervém, podendo inclusive sugerir propostas para fins de dirigir a discussão. "Na conciliação o objetivo é o acordo, ou seja, as partes, mesmo adversárias, devem chegar a um acordo para evitar o processo judicial ou para nele pôr um ponto final, se porventura ele já existe" (SPENGLER, 2016, p. 75).

O conciliador auxiliará as partes a chegarem a um acordo, interferindo, sugerindo e aconselhando, para resolver o conflito, alertando sobre as consequências, e sobre cada uma das possibilidades que se apresenta. Algumas alterações legislativas 
destacam-se como iniciativas no sentido de inserir a conciliação como meio consensual de resolução de conflitos. A Lei no 8.952/94 alterou o Código de Processo Civil de forma a incluir no procedimento ordinário uma audiência preliminar de conciliação, como momento para conciliar os litigantes e sanar o processo. Compete ao juiz tentar conciliar as partes, perguntando se estão dispostas a resolver de forma amigável o litígio e, a partir disso, deve levar a solução proposta por uma parte à outra, ou ele próprio pode sugerir uma ou mais soluções viáveis, sempre no sentido da composição amigável da demanda, sem pressionar qualquer das partes para que realize o acordo.

Embora a revogada Lei o 7.244/84, que instituiu os Juizados Especiais de Pequenas Causas, ter ampliado as formas de acesso ao Judiciário, em especial para aqueles menos favorecidos economicamente, foi com a Constituição Federal de 1988 que os contornos da mudança ganharam força. Sob os auspícios da denominada "terceira onda" de reformas propostas por Mauro Cappelletti e Bryant Garth, o constituinte inseriu o mandamento constitucional do art. 98, determinando a criação dos Juizados Especiais estaduais e federais, tanto na seara cível quanto na criminal:

Art. 98. A União, no Distrito Federal e nos Territórios, e os Estados criarão:

I - juizados especiais, providos por juízes togados, ou togados e leigos, competentes para a conciliação, o julgamento e a execução de causas cíveis de menor complexidade e infrações penais de menor potencial ofensivo, mediante os procedimentos oral e sumaríssimo, permitidos, nas hipóteses previstas em lei, a transação e o julgamento de recursos por turmas de juízes de primeiro grau;

$\S 1$ ํㅡㄹ federal disporá sobre a criação de juizados especiais no âmbito da Justiça Federal (BRASIL, 1988).

A partir de então, no ano de 1995, foi criada a Lei no 9.099, cuidando dos Juizados Especiais Cíveis e Criminais, e em 2009 foi criada a Lei oำ 12.153, que trata dos Juizados Especiais da Fazenda Pública, constituindo o sistema dos Juizados Especiais dos Estados, do Distrito Federal e dos Territórios. Trata-se de um sistema inovador para a solução de conflitos de menor complexidade, buscando a conciliação das partes sempre que possível:

Art. 1ํㅡㄴ Juizados Especiais Cíveis e Criminais, órgãos da Justiça 
Ordinária, serão criados pela União, no Distrito Federal e nos Territórios, e pelos Estados, para conciliação, processo, julgamento e execução, nas causas de sua competência.

Art. $2^{\circ} \mathrm{O}$ processo orientar-se-á pelos critérios da oralidade, simplicidade, informalidade, economia processual e celeridade, buscando, sempre que possível, a conciliação ou a transação (BRASIL, 1995).

O que se verifica é a tentativa de simplificação no procedimento, com o objetivo de proporcionar maior acesso ao Judiciário na busca de uma resolução de conflitos mais eficiente e satisfatória. A Lei no 9.099/95 prevê o uso da conciliação, que muitas vezes abranda o procedimento judicial. A conciliação inserida ao procedimento especial dos Juizados tem o viés de dar maior efetividade aos direitos fundamentais, primando pela celeridade, a fim de diminuir as dificuldades encontradas nos processos.

No âmbito federal, foram instituídos os Juizados Especiais Cíveis e Criminais pela Lei ํㅜ 10.259, de 12 de julho de 2001.

Nesta perspectiva, o Juizado Especial Federal foi preconizado e concebido para ser, além de justiça social, o locus da justiça conciliativa nos conflitos do Poder Público Federal, funcionando assim como instrumento propulsor da "cidadania social". Guarda, na sua mais profunda genealogia, o embrião da democratização e da igualdade material (VAZ, 2016, p. 185) [grifo do autor].

Ela traz expressamente a competência dos representantes judiciais de entes federais para celebrar acordos e destaca o procedimento na consensualidade.

O Juizado Especial Federal (JEF) tem como função possibilitar o acesso e ampliar a concretização dos direitos fundamentais nas situações de conflitos de limitação e morosidade no reconhecimento desses direitos. Aliás, a Resolução oㅡ 125/2010 do Conselho Nacional de Justiça por considerar a mediação e a conciliação instrumentos de pacificação social e de resolução e prevenção de conflitos trouxe subsídios para as conciliações na Justiça Federal em processos em face do Instituto Nacional de Seguro Social (INSS).

O Juizado Especial Federal, principalmente na sua face conciliatória, é o locus privilegiado para o exercício da igualdade de oportunidades por meio do empoderamento das partes diante do desequilíbrio que se 
estabelece pela própria ordem dos conflitos de natureza previdenciária. Os contendores são o particular e o Poder Público, aquele buscando uma prestação social que este tende a lhe negar segundo fundamentos eficientistas e utilitaristas encontradiços nas respostas técnicas caracterizadas por uma verticalidade descendente e que contrastam com a demanda política apresentada pelo cidadão (VAZ, 2016, p. 202203).

A conciliação poderá ser extrajudicial e o acordo pode ser homologado pelo juiz. No entanto, a regra é a conciliação judicial, realizada pelo juiz ou pelo conciliador.

No sistema conciliatório estruturado para o Brasil a presença física do juiz na audiência de conciliação não é necessária. Seu papel de supervisor pode se desenvolver a despeito de sua presença física na audiência, bastando que esteja disponível, no seu gabinete ou nas dependências do foro, para solucionar eventuais problemas (VAZ, 2016, p. 351).

Verifica-se, portanto, que o objetivo da conciliação é o acordo. Nessa perspectiva, a União Federal já vem adotando algumas práticas, conforme se verifica pela Câmara de Conciliação e Arbitragem da Administração Federal - CCAF, criada em 27 de setembro de 2007, pelo Ato Regimental 5/2007, que após alterações, encontra-se prevista no art. 18 do Decreto no 7.392/2010:

Art. 18. A Câmara de Conciliação e Arbitragem da Administração Federal compete:

I- avaliar a admissibilidade dos pedidos de resolução de conflitos, por meio de conciliação, no âmbito da Advocacia-Geral da União;

II- requisitar aos órgãos e entidades da Administração Pública Federal informações para subsidiar sua atuação;

III- dirimir, por meio de conciliação, as controvérsias entre órgãos e entidades da Administração Pública Federal, bem como entre esses e a Administração Pública dos Estados, do Distrito Federal, e dos Municípios;

IV- buscar a solução de conflitos judicializados, nos casos remetidos pelos Ministros dos Tribunais Superiores e demais membros do Judiciário, ou por proposta dos órgãos de direção superior que atuam no contencioso judicial;

V- promover, quando couber, a celebração de Termo de Ajustamento de Conduta nos casos submetidos a procedimento conciliatório;

VI- propor, quando couber, ao Consultor-Geral da União o arbitramento das controvérsias não solucionadas por conciliação; e

VII- orientar e supervisionar as atividades conciliatórias no âmbito das Consultorias Jurídicas nos Estados (BRASIL, 2010). 
Alguns casos resolvidos pela CCAF, os quais foram publicados pela AdvocaciaGeral da União, são descritos por Souza (2012, p. 281-286). Entre 2004 a 2006 foram encerrados 11 casos, um por arbitragem, quatro por desistência de uma das partes, nos demais houve conciliação, sendo que a maioria eram litígios entre o INSS ou Receita Federal e Administração Federal indireta. Entre 2007 a 2008 foram resolvidos 31 casos por conciliação, e 6 por arbitragem. Dentre eles, alguns complexos, como conflitos envolvendo bem imóveis, débitos previdenciários, políticas públicas.

Segundo a autora, a CCAF vem dando concretude a soluções consensuais, mas precisa de aprimoramentos no seu procedimento e metodologia. A novidade trazida pela Lei no 13.140 de 2015 é a possibilidade de essas câmaras avaliarem a admissibilidade dos pedidos de resolução de conflitos entre particular e Poder Público, por meio da composição. Pode representar inclusive a fundamentação para as conciliações e mediações na via administrativa.

De acordo com o relatório "Justiça em Números", de 2017, publicado pelo Conselho Nacional de Justiça, "a conciliação é uma política adotada pelo CNJ desde 2006, com a implantação do Movimento pela Conciliação em agosto daquele ano. Há nove anos o Conselho promove as Semanas Nacionais pela Conciliação, momento em que os tribunais são incentivados a juntar as partes e promover acordos nas fases préprocessual e processual" (CNJ, 2017, p. 123). Dessa forma, o CNJ estimula e orienta os órgãos judiciários no caminho da composição de conflitos pela conciliação, além de incentivar as autoridades públicas e os operadores do direito para a necessidade de rever conceitos.

Além de tais normativos, tem-se o novo Código de Processo Civil, que dentre seus objetivos, nos parágrafos do art. $3^{\circ}$ destaca a solução consensual dos conflitos:

$\S 2^{\circ}$ O Estado promoverá, sempre que possível, a solução consensual dos conflitos.

$\S 3^{\circ} \mathrm{A}$ conciliação, a mediação e outros métodos de solução consensual de conflitos deverão ser estimulados por juízes, advogados, defensores públicos e membros do Ministério Público, inclusive no curso do processo judicial (BRASIL, 2015). 
De outra banda, o art. 334 do novo Código de Processo Civil traz uma expressiva alteração nos trâmites processuais, pois insere a mediação e a conciliação no procedimento judicial: "se a petição inicial preencher os requisitos essenciais e não for o caso de improcedência liminar do pedido, o juiz designará audiência de conciliação ou de mediação com antecedência mínima de 30 (trinta) dias, devendo ser citado o réu com pelo menos 20 (vinte) dias de antecedência" (BRASIL, 2015).

Inclui, portanto, no procedimento comum, uma etapa inicial em que se realiza uma audiência de conciliação ou mediação antes do prazo de apresentação de defesa pelo réu. A audiência não ocorrerá se não for possível a transação ou se as partes manifestarem discordância na realização do mecanismo. Se a audiência for marcada e a parte faltar, a mesma será sancionada com multa. De acordo com Vaz, essa audiência prévia de conciliação, pode contribuir para o incremento da autocomposição no JEF, tendo em vista que na maioria das vezes ela não vem ocorrendo, sendo designada somente se a parte ré apresentar proposta de conciliação, e muitas vezes não é designada, dirigindo-se a parte sobre o acordo de forma escrita.

Quanto à obrigatoriedade ou não da audiência de conciliação no JEF, há divergências, pois muitos entendem que ela é dispensável, por atrasar o andamento dos processos, e pelo fato de que o acordo pode ocorrer na audiência de instrução. A regra geral deve ser a designação de audiência prévia de conciliação, e o juiz deverá encontrar na legislação o fundamento para não designá-la, "na triagem dos casos, os parâmetros operacionais serão, além das hipóteses previstas no § 4º I e II, do art. 334 do NCPC, a definição administrativa das situações em que a própria Administração, por ato normativo, explicita os casos em que é possível a conciliação". A conciliação será efetuada pelo conciliador sob a supervisão do juiz (VAZ, 2016, p. 312 - 323).

Certo é que a mediação e a conciliação não vêm expostas no atual CPC como obrigatórias, o que deve ser comemorado. Ainda que o art. 334, ao dispor sobre a audiência de conciliação ou de mediação faça referência ao não comparecimento sem justificativa de uma das partes como "ato atentatório à dignidade da justiça" e disponha sobre multa pecuniária a título de sanção, tem-se que a mediação e a conciliação não são obrigatórias uma vez que o mesmo artigo em seu §4ㄴ. incisos I e II, e o §5 oferecem remédio para aquele(s) que não quer(em) comparecer ao ato. Diante de tal redação o artigo insiste na realização da conciliação e mediação mas permite que ela seja recusada na petição inicial pela 
parte autora e em petição fundamentada, no prazo de 10 dias antes da audiência, pela parte requerida (SPENGLER, 2006, p. 116-117).

A não imposição da mediação ou conciliação revela os propósitos destes mecanismos, os quais trazem justamente a característica da escolha dos conflitantes. Assim, tanto a mediação como a conciliação, por serem meios autocompositivos, proporcionam acordos que são frutos de um entendimento entre as partes e não de uma imposição.

O que se defende é uma nova concepção do Direito e da Justiça, cujas diretrizes estruturantes estejam baseadas em ideais distributivos, nas diferenças, nas vulnerabilidades, na espiritualidade e no amor, que nos investe a todos na condição de soldados de uma batalha por melhor qualidade de vida dos excluídos (VAZ, 2016, p. 211-212).

Nesse aspecto, a solidariedade, a compreensão do "outro", e o amor pode conduzir a uma cultura de paz, mediante a colaboração do cidadão e do sistema jurídico como um todo. Portanto, nos meios autocompositivos, não haverá um perdedor e um ganhador como ocorre no modelo jurisdicional de Estado de Direito.

É significativo que um processo dirigido para a conciliação - ao contrário do processo judicial, que geralmente declara uma parte "vencedora" e a outra "vencida" - ofereça a possibilidade de que as causas mais profundas de um litígio sejam examinadas e restaurado um relacionamento complexo e prolongado (CAPPELLETTI; GARTH, 1988, p. 84).

Nos meios autocompositivos, o foco é a construção de uma solução em que os conflitantes fiquem satisfeitos em relação as suas necessidades. Dessa forma, a solução consensuada possui vantagem pelo fato de que as partes decidem, criando uma maior facilidade no comprimento voluntário do acordo. Além disso, elas permitem maior flexibilidade aos procedimentos e ao direito substantivo, sem ficar adstritas a jurisprudências, e ainda permite a equidade, encontrada uma solução na regra de justiça que se amolda ao caso, ela pode ser aplicada (VAZ, 2016, p. 367-369).

A Resolução do CNJ no 125/2010 também prevê no art. 7º a criação dos Núcleos 
Permanentes de Métodos Consensuais de Solução de Conflitos, e descreve uma série de atribuições, como a atuação dos profissionais que irão atuar nos núcleos, aos quais compreende o desenvolvimento da Política Judiciária de tratamento dos conflitos de interesses, desde o planejamento, a implementação e a interlocução com outros Tribunais e órgãos da rede. Outra atribuição é o incentivo ou promoção de capacitação dos membros, e aqui cabe ressalva importante: "nesse sentido, os profissionais que formarão e acompanharão serventuárias, mediadores e conciliadores precisarão estar despidos da "cultura da sentença", do espírito paternalista de "resolver pelos/para outros"'” (SPENGLER, 2016, p. 81-82).

Além de propor ao Tribunal a elaboração de convênios e parcerias com entes públicos e privados para atender aos fins da Resolução, a Emenda № 2 de 2016 incluiu os incisos VII e VIII, atribuindo também a criação e manutenção de cadastro de mediadores e conciliadores, regulamentando o processo de inscrição e de desligamento, e poderão regulamentar, se for o caso, a remuneração de conciliadores e mediadores, pois

[...] uma vez que muitos mediadores, habilidosos e técnicos precisam ser remunerados para fins de manter sua subsistência, deixando, desse modo, de realizar o trabalho junto ao Judiciário por falta de retorno financeiro. Perde-se assim, os melhores profissionais. Por outro lado, a mediação é um procedimento difícil, tantas vezes penoso, que requer atualização constante o que significa estudo, compra de livros e deslocamento. Tais fatores exigem tempo e dinheiro, o que nem sempre vem atrelado ao trabalho voluntário, modo como vem sendo vista, tratada e organizada a atividade dos mediadores (SPENGLER, 2016, p. 81).

O artigo $8^{\circ}$ da Resolução sub oculis também sofreu alteração pela Emenda ํㅡ 2, de 2016, a qual trata especificadamente da criação dos Centros Judiciários de Solução de Conflitos e Cidadania:

Art. 8 Os tribunais deverão criar os Centros Judiciários de Solução de Conflitos e Cidadania (Centros ou Cejuscs), unidades do Poder Judiciário, preferencialmente, responsáveis pela realização ou gestão das sessões e audiências de conciliação e mediação que estejam a cargo de conciliadores e mediadores, bem como pelo atendimento e orientação ao cidadão. (Redação dada pela Emenda $n^{\circ}$ 2, de 08.03.16) (CNJ, 2010). 
Assim, por intermédio da Resolução CNJ no 125/2010, foram criados os Centros Judiciários de Solução de Conflitos e Cidadania (CEJUSCs). Conforme o relatório Justiça em Números 2017, do Conselho Nacional de Justiça, "na Justiça Estadual, havia, ao final do ano de 2016, 905 CEJUSCs instalados" (CNJ, 2017, p. 123). No âmbito federal, Vaz (2016, p. 342), "foram também criados os Centros Judiciários de Solução de Conflitos e Cidadania - CEJUSCONS, em quase todas as Subseções Judiciárias. No ano de 2014, nas diversas Subseções Judiciárias da Justiça Federal, foram designadas 37.265 audiências, com 25.801 audiências efetivamente realizadas e 18.783 acordos firmados".

De acordo com o autor, os CEJUSCONS visam retirar das varas do JEF o trabalho dirigido à conciliação, pois ele é realizado apartado. A ideia era que os CEJUSCONS realizassem uma triagem de modo a definir qual mecanismo mais adequado para aquele conflito, mas na prática a atuação é apenas sobre os conflitos judicializados. A vara seleciona o processo e encaminha a CEJUSCONS, que toma as providências para a audiência conciliatória, o juiz coordenador irá apenas homologar o eventual acordo. São realizados mais conciliações processuais, e poucos préprocessuais (VAZ, 2016, p. 342-345).

É possível contar com a Justiça Itinerante, conforme descreve o $§ 3^{\circ}$ do artigo $8^{\circ}$ da Resolução $n^{\circ}$ 125/2010, segundo a qual "os tribunais poderão, enquanto não instalados os Centros nas Comarcas, Regiões, Subseções Judiciárias e nos Juízos do interior dos estados, implantar o procedimento de Conciliação e Mediação itinerante, utilizando-se de Conciliadores e Mediadores cadastrados". Assim, as sessões de mediação e conciliação podem ser realizadas em diferentes locais, com objetivo de levar a cultura da pacificação.

Há, também, a questão dos setores de tratamento de conflitos. Conforme art. 10 da Resolução, "cada unidade dos Centros Judiciários de Solução de Conflitos e Cidadania deverá obrigatoriamente abranger setor de solução de conflitos préprocessual, de solução de conflitos processual e de cidadania".

Ao setor de tratamento de conflitos pré-processual incumbe-se a recepção dos casos que digam respeito à matéria cível, de família, previdenciária e de competência dos Juizados Especiais Cíveis e Fazendários. O procedimento diz respeito à apresentação da 
reclamação ao servidor que, depois de reduzi-la a termo, emite a cartaconvite à parte contrária, apontando data, horário e local da sessão de conciliação ou mediação. [...] $O$ tratamento de conflitos na fase préprocessual torna-se vantajoso, uma vez que, na maioria das vezes, antes do ajuizamento da ação, os ânimos estão mais acomodados, facilitando a comunicação mediada e um possível acordo anterior à instauração da lide. Além disso, se possível o consenso entre os conflitantes (seja pela reconciliação, seja pelo acordo), um processo judicial pode ser evitado ocorrendo, aqui sim, a diminuição do contencioso judicial e a celeridade na resposta (SPENGLER, 2016, p. 84-85).

O primeiro setor será o da cidadania, no qual ocorrerá a orientação do cidadão em relação ao melhor método de tratamento de seu conflito, podendo escolher antes de iniciar a sessão. No caso de não haver acordo na fase pré-processual, o conflitante será informado das possibilidades de tratamento de conflitos. Nesse caminho cresce a importância da atuação dos profissionais responsáveis por ajudar os conflitantes na escolha do método mais adequado. Trata-se de uma conduta diferenciada que precisa ser fomentada para que se tenha uma mudança de paradigma: cultura da sentença para cultura da paz (SPENGLER, 2016, p. 84-88).

Sendo a solução consensual compromisso do Estado, que está obrigado a criar procedimentos para promovê-la; dos juízes, que estão obrigados a incentivar as partes a buscá-la; dos advogados, que devem orientar seus clientes para a sua prévia tentativa, fecha-se o círculo em torno da autocomposição, deixando esta de ser uma mera possibilidade para se tornar um dever inerente às atribuições de cada um destes atores do processo judicial (VAZ, 2016, p. 307).

Nesse sentido, a Resolução CNJ no 125 de 2010, no artigo 6º́, descreve a importância da construção de redes de cooperação:

Art. 6ำ Para desenvolvimento dessa rede, caberá ao CNJ: [...] V - buscar a cooperação dos órgãos públicos competentes e das instituições públicas e privadas da área de ensino, para a criação de disciplinas que propiciem o surgimento da cultura da solução pacífica dos conflitos, bem como que, nas Escolas de Magistratura, haja módulo voltado aos métodos consensuais de solução de conflitos, no curso de iniciação funcional e no curso de aperfeiçoamento; VI - estabelecer interlocução com a Ordem dos Advogados do Brasil, Defensorias Públicas, Procuradorias e Ministério Público, estimulando sua participação nos Centros Judiciários de Solução de Conflitos e Cidadania e valorizando a 
atuação na prevenção dos litígios; VII - realizar gestão junto às empresas, públicas e privadas, bem como junto às agências reguladoras de serviços públicos, a fim de implementar práticas autocompositivas e desenvolver acompanhamento estatístico, com a instituição de banco de dados para visualização de resultados, conferindo selo de qualidade; VIII - atuar junto aos entes públicos de modo a estimular a conciliação, em especial nas demandas que envolvam matérias sedimentadas pela jurisprudência. (Incluído pela Emenda no 2, de 08.03.16) (CNJ, 2010).

\section{O referido artigo e seus incisos deixam claro que é necessária a colaboração de} todos para a pacificação social, inclusive ao Poder Público.

As observações precedentes, assim como a já apontada necessidade de interação entre o Poder Judiciário, outros órgãos estatais e a sociedade civil, apontam para a oportunidade das concepções que propõe a instauração de um espécie de diálogo institucional, que, embora não possa, no nosso sentir, justificar uma exclusão do controle judicial, à feição de uma nova doutrina da separação dos Poderes, apresenta a faceta positiva, desde que bem manejado, de, mediante 0 aproveitamento máximo das capacidades institucionais de cada ator envolvido, auxiliar na promoção da máxima efetividade dos direitos fundamentais. Cumpre registrar, todavia, de que se cuida, de certo modo, de dar cumprimento ao dever de cooperação entre os órgãos estatais. Nesse contexto, situa-se, em caráter ilustrativo, a utilização técnicas de prevenção e mesmo de mecanismos alternativos (não jurisdicionais) de solução dos conflitos em matéria de direitos sociais, tal como sugere, à luz do caso do direito à saúde, Ângela Carlini (SARLET, 2015, p. 380).

Nessa perspectiva, o Conselho Nacional de Justiça 2017 apresenta à esfera pública os índices de conciliação:

A Justiça que mais faz conciliação é a Trabalhista, que consegue solucionar $26 \%$ de seus casos por meio de acordo - valor que aumenta para $40 \%$ quando apenas a fase de conhecimento de primeiro grau é considerada. O TRT19 apresentou o maior índice de conciliação do Poder Judiciário, com $36 \%$ de sentenças homologatórias de acordo. $\mathrm{Na}$ fase de conhecimento dos juizados especiais, o índice de conciliação foi de $16 \%$, sendo de $19 \%$ na Justiça Estadual e de $6 \%$ na Justiça Federal. $\mathrm{Na}$ execução, os índices são menores e alcançam 5\%. No 1 grau, a conciliação foi de $13,6 \%$. No $2^{\circ}$ grau, a conciliação é praticamente inexistente, apresentando índices muito baixos em todos os segmentos de justiça [...], sendo que as sentenças homologatórias de acordo representaram, em 2016, apenas $0,4 \%$ do total de processos julgados. Não houve variações significativas no indicador de conciliação no $2^{\circ}$ e $1^{\circ}$ grau em relação ao ano anterior, observando-se, respectivamente, aumento de 0,1 ponto percentual e 0,6 ponto percentual. Para completar 
os dados que compõem o indicador de conciliação, foram separadas as fases de conhecimento e de execução [...]. Observa-se que a conciliação ocorre mais frequentemente na fase de conhecimento (17\%), sendo pouco frequente na execução (5\%). A Justiça mais conciliadora, a trabalhista, consegue solucionar $40 \%$ de seus casos de conhecimento por meio de conciliação. A Justiça Federal apresenta percentuais mais próximos entre ambas as fases $(6 \%$ no conhecimento e $8 \%$ na execução) (CNJ, Justiça em números 2017, 2017, p. 124).

Percebe-se que os Juizados Especiais Federais ainda não possuem um percentual satisfatório de acordos, sendo que

Os conflitos que são tratados no JEF têm, grosso modo, o seguinte perfil: em torno de $70 \%$ representam insatisfação quanto a direitos sociais previdenciários e, portanto, têm o INSS no polo passivo. Os outros $10 \%$ são conflitos versando sobre contratos bancários, danos morais, redução de dívida e outras discussões em torno de contratos de financiamento firmados com a CEF. Os $20 \%$ restantes são conflitos entre servidores públicos e a União Federal e suas Autarquias acerca de direitos indenizatórios e remuneratórios decorrentes da relação de trabalho, e de natureza fiscal, tendo como autor o contribuinte e ré a Fazenda Nacional (VAZ, 2016, p. 257).

Em relação às ações que chegam ao Juizado, Vaz (2016, p. 255-259) entende que, de uma maneira geral, em um dos polos está o Poder Público, e em outro, o particular reivindicando uma prestação social. Tais conflitos são de ordem pecuniária, nos quais praticamente não se discute questões sentimentais, sendo, portanto, a abordagem adversarial.

Estando o JEF colonizado por pretensões de direitos sociais verticadas em face do INSS $(73,1 \%$ dos casos), e sendo este ente público, portanto, o litigante habitual estruturalmente empoderado, o sucesso de uma política de conciliações pressupõe que a estrutura comunicativa deste microssistema opere estrategicamente no sentido do empoderamento (empowerment) da parte hipossuficiente (litigante ocasional), condição de possibilidade para o equilíbrio desejável no diálogo que antecede o consenso (VAZ, 2016, p. 400).

Questão trazida pela doutrina é quanto a um possível desequilíbrio entre as partes, por ser uma delas o Poder Público. Essa situação acabaria por influenciar a parte de menor poder, pois esta, em razão de dificuldades financeiras, poderia aceitar 
as propostas da outra. Nesse sentido, e equiparação das partes é essencial, de sorte que

O empoderamento das partes, sobretudo as mais fragilizadas, deve abarcar os propósitos de possibilitar que: 1. entendam o conflito em seus entornos; 2. conheçam os modelos decisórios disponíveis; 3. escolham o tipo de solução que pretendem; 4. se posicionem conscientemente quanto a essa solução, sopesando possíveis ganhos e perdas; e 5 . participem efetivamente do diálogo comunicativo que pretende a decisão ou o acordo, conforme o caso, fazendo valer suas pretensões de comprovação da veracidade e juridicidade do alegado (VAZ, 2016, p. 205).

No momento em que oportuniza o empoderamento das partes, estabelece-se um ponto de equilíbrio para que, a partir de então, o diálogo seja frutífero.

A equiparação das partes é fundamental porque assume o compromisso com a atenuação (se não é possível falar em eliminação) das disparidades em amplo sentido existentes entre os grandes litigantes, entidades públicas que se enquadram no conceito de litigantes habituais na referida justiça, tais como o INSS e a União Federal, e os litigantes ocasionais, em geral hipossuficientes, embora não necessariamente no aspecto econômico (VAZ, 2016, p. 205).

A hipossuficiência das partes é um problema comum à autocomposição e à adjudicação. Representações fracas e mal elaboradas tanto podem distorcer um juízo adjudicatório como levar a um acordo com concessões unilaterais. Por isso, ambos devem albergar mecanismos que permitam arredar os inconvenientes do desequilíbrio de poder entre os conflitantes (VAZ, 2016, p. 396). Ao conciliador e ao mediador cabe oportunizar o equilíbrio, como ensina Souza (2012, p. 76), "a forma de atuação do mediador deve contrabalançar este desequilíbrio, já que ele pode afetar a capacidade de participação da parte com menor poder na construção da solução consensual". Percebe-se que o eventual desequilíbrio entre as partes não deve ser justificativa para a não utilização dos meios autocompositivos nos conflitos que envolvem a Administração Pública, tendo em vista que nos processos judiciais tal fato pode ocorrer também.

A conciliação se revela uma forma para se tentar um acordo voluntário pelas próprias partes com a intervenção de um terceiro que gerencia a discussão. Conforme 
Souza (2012, p. 160), uma das dificuldades na implementação das práticas de resolução de conflitos quando envolvem o Poder Público é que "existe grande receio de assunção de responsabilidade em nível pessoal pela celebração de acordos - e nenhuma cobrança pela omissão em realizá-la quando era o caso de realizar o acordo e evitar assim a realização de trabalhos e despesas adicionais desnecessárias para o erário". De acordo com Vaz (2016, p. 283-284), esse receio acompanhado da falta de estrutura ou minimização do serviço público, faz com haja uma retração dos Procuradores Públicos em relação a políticas conciliatórias.

Além disso, pela própria cultura do litígio há um senso comum de que inexiste o dever de analisar a possibilidade de solução autocompositiva, no entanto, a doutrina administrativa entende que tal avaliação trata-se de um dever, em razão dos princípios da eficiência, proporcionalidade e da razoável duração do processo. Na esteira de Souza (2012, p. 164), são necessárias normas suficientemente claras acerca de todo o procedimento que envolve a utilização dos meios consensuais, assim como treinamento e terceiros que facilitem a comunicação entre as partes.

A mediação ou a conciliação de conflitos relacionados a políticas públicas na esfera administrativa pode ser utilizada numa grande variedade de situações. [...] $O$ meios consensuais de solução de conflitos tanto podem ser utilizados quando um dos envolvidos no conflito é um ente público e o outro é um particular, como é muito comum ocorrer nos processos de fiscalização e licenciamento, como nos processos envolvendo a reparação de danos decorrentes da lesão a bens de interesse público. [...] Ainda, é possível a utilização de meios consensuais no processo disciplinar em que a pequena gravidade da possível infração praticada pelo servidor público recomenda uma solução mais voltada à adequação da conduta que à punição pura e simples do servidor, como vem ocorrendo, por exemplo, no Município de Belo Horizonte. É perfeitamente cabível, do mesmo modo, a utilização de meios consensuais para resolução de eventual conflito quanto ao valor do imóvel no procedimento de desapropriação, como vem fazendo o Município de São Paulo. Por fim, embora a pesquisa não tenha identificado uma única iniciativa neste sentido, é plenamente plausível (e altamente recomendável) a utilização de meios consensuais para solucionar conflitos entre Administração Pública e cidadão ou ente privado em qualquer processo individual no qual seja exercido o direito de petição, seja para requerer a prática, modificação, anulação ou revogação de um ato, seja para requerer uma indenização por dano decorrente de atuação do Poder Público (SOUZA, 2012, p. 185-187). 
A autora cita uma iniciativa do maior litigante judicial, o Instituto Nacional do Seguro Social, o qual lançou no ano de 2008 o "Programa de Redução de Demandas Judiciais do INSS", com o objetivo de diminuir $40 \%$ por ano a quantidade de ações contra 0 instituto. A proposta é identificar as agências com alto nível de rejeição de benefícios, e após, os casos não aceitos seriam analisados para que a Advocacia-Geral da União e Previdência façam nova interpretação da legislação previdenciária. Trata-se de uma tentativa de melhoria, mas "não existe consultoria que substitua um sistema estruturado de resolução de conflitos na esfera administrativa" (SOUZA, 2012, p. 228229). No mesmo sentido, $\operatorname{Vaz}(2016$, p. 232) refere que "uma reforma no procedimento administrativo, para que se inclua a possibilidade de conciliação diretamente na instância administrativa, medidas que possibilitariam a redução das demandas judiciarizadas".

Embora se reconheça que, nos litígios de menor valor e complexidade, a conciliação tem mais probabilidade de ocorrer, devido ao grau diminuto do acirramento dos ânimos das partes e às circunstâncias da disputa, não se pode descartar a possibilidade de acontecer em qualquer tipo de conflito, mesmo nos mais difíceis e/ou que envolvam grande interesse econômico (VAZ, 2016, p. 369).

A Justiça Federal da 4ํㅜ Região já possui uma trajetória no âmbito da conciliação. Algumas ações implementadas podem ser destacadas, como o projeto de conciliação nos processos do Sistema Financeiro de Habitação (PROJECON) implementado pelo TRF4․ Em 2005, o TRF4 instituiu o SISTCON - Sistema de Conciliação, incentivando a conciliação. Dando cumprimento a Resolução CNJ 125/2010, o TRF4 adequou e ampliou o sistema de conciliação da Justiça Federal da 4ํㅜ região, e o SISTCON passou a atuar como Núcleo Permanente de Métodos Consensuais de Solução de Conflitos (VAZ, 2016, p. 341-342).

Cabe salientar os efeitos positivos que a conciliação surtiu na Justiça Federal: na busca da pacificação social, visando à prevenção e solução de litígio; na economia processual; na satisfação almejada pelas partes, quanto à rápida decisão alcançada, pela celeridade processual; na facilidade do acesso à justiça pela parte mais frágil da relação, por saber que há um método alternativo para resolver os conflitos de baixa complexidade; e principalmente pela informalidade do sistema. Frisa-se ainda que "a conciliação não implica risco, a ponto de prejudicar uma 
das partes no litígio caso não aceitem a conciliação e decidam que o processo retorne à vara de origem, para dar prosseguimento normal ao caso conflitante (AQUINO, 2014) (FOPPA; DUQUE, 2017, p. 14).

Ainda no sentido de ações realizadas pela Justiça Federal da $4^{\circ}$ Região, destacam-se:

As Seções Judiciárias do Rio Grande do Sul, Paraná e Santa Catarina implantaram os Sistemas Integrados de Perícias Médicas e de Conciliações. Atualmente, estão em pleno funcionamento: o Sistema de Conciliação Pré-Processual - SICOPP-PR, o Sistema de Perícias Médicas e de Conciliações Pré-Processuais nas matérias de Competência das Varas e JEFs Previdenciários - SICOPREV-RS e 0 Sistema de Conciliações e Perícias Médicas - SICOPEM-SC. [...] O TRF4 conta com o Gabinete de Conciliação do INSS, instalado em 2009 [...] A parceria vem alcançando excelentes resultados dando, pela via conciliatória, uma solução rápida, econômica e definitiva aos recursos que tramitam nos gabinetes previdenciários. [...] "Fórum de Conciliação Virtual". A ferramenta eletrônica permite a aproximação das partes para a resolução dos conflitos sem a necessidade de comparecimento na Justiça para audiências de conciliação em Centros Judiciários de Solução de Conflitos e Cidadania ou nas Varas Federais (VAZ, 2016, p. 354-358).

Além disso, a Justiça Federal da 4ํ Região será responsável no período de 2015-2020 pelo macrodesafio proposto pelo CNJ no sentido de adotar soluções alternativas, meios extrajudiciais para resolução de conflitos no âmbito da Justiça Federal. Assim, foi criada a 26 ${ }^{\underline{a}}$ Vara Federal de Porto Alegre, que iniciou atividades em 10 de julho de 2014, na Subseção Judiciária de Porto Alegre - SJ/RS, com quadro próprio de magistrados e servidores. A Vara Federal de Conciliação é vinculada ao Centro Judiciário de Solução de Conflitos e Cidadania de Porto Alegre (CEJUSCON), com orientação do Sistema de Conciliações (SISTCON) do TRF4.

Ela somente recebe processos por redistribuição, pois não tem competência exclusiva para julgamento de algumas matérias. Realizada a audiência com resultado positivo, ou encerrado o Fórum de Conciliação Virtual com acordo, é realizada a sentença homologatória. O tempo médio de tramitação dos processos, desde a redistribuição até a homologação do acordo era de 94 dias em 2004, e de julho de 2014 até abril de 2015 o INSS pagou $R \$ 16.095 .357,39$ decorrentes de acordos, os quais são 
fechados no percentual médio de $95 \%$ do efetivamente devido, tendo assim, demonstrado resultado positivo (VAZ, 2016, p. 360-363).

Quando da criação da Vara Federal de Conciliação, o presidente do Tribunal Regional Federal da 4⿳亠丷a Região (TRF4), desembargador federal Tadaaqui Hirose, encerrou a solenidade refletindo sobre sua carreira, fazendo uma reflexão para o futuro:

Sou da época em que o poder público não fazia acordo. Os anos passaram e hoje verificamos uma grande mudança no Judiciário e eu seus atores. Acredito que estejamos caminhando, com a conciliação, onde não há vencidos ou vencedores, para um período em que tenhamos mais paz social neste país (BRASIL, Seção Judiciária do Rio Grande do Sul, 2014).

O Relatório "Justiça em Números 2017 - Destaques" com base nos dados de 2016, publicado pelo Conselho Nacional de Justiça, descreve alguns índices de acordos homologados no âmbito das unidades judiciárias de primeiro grau, justiça estadual, federal, trabalhista e eleitoral, sendo que

Para cada 100 processos judiciais encerrados em 2016 (com sentença ou decisão terminativa), 12 conflitos foram resolvidos por meio de acordo entre as partes em disputa. As estatísticas de 2016 mostram que a prática da conciliação está consagrada na Justiça do Trabalho, ramo do Poder Judiciário em que o número de conciliações corresponde a $26 \%$ do total de ações concluídas. O Tribunal Regional do Trabalho da 19a Região (TRT19) é o recordista nesse quesito. No estado de Alagoas, as conciliações propostas alcançam 36\% de êxito. Quanto maior a informalidade da instância, a disputa tem mais chances de ser resolvida por meio de acordo. Nos Juizados Especiais, em que a presença de um advogado não é exigida, $16 \%$ das divergências terminam na chamada via da conciliação. O percentual cai quando o processo chega ao primeiro grau para $13,6 \%$ e para apenas $0,4 \%$ na segunda instância. $O$ índice de conciliação também é maior na fase de conhecimento: 17\% dos casos foram firmados em 2016. Nessa etapa processual são ouvidas testemunhas e recolhidas provas. Apenas $5 \%$ dos acordos ocorreram durante a fase de execução, quando um devedor é cobrado por suas dívidas, por exemplo. Em vigor desde março de 2016, o novo texto do Código de Processo Civil (CPC) prevê que a conciliação seja tentada antes de o conflito ser judicializado. No entanto, essa nova orientação da lei ainda não se refletiu na quantidade de conciliações realizadas após o início formal dos processos. O crescimento do número de autocomposições de 2015 para 2016 foi de apenas 0,8 ponto percentual (CNJ, 2017, p. 16). 
Apesar de a legislação inovar no sentido da realização de acordos no âmbito federal, e da já utilização de mecanismos consensuais, são necessárias algumas práticas para implementá-las de forma que produzam resultados mais satisfatórios, tendo em vista que grande número de litígios chegam aos juizados desnecessariamente.

Os juízes de Juizado precisam reciclar suas mentalidades, demasiada e profundamente dominadas pelas tarefas tradicionais da justiça civil e penal, para se adaptar a uma nova maneira de compreender e aplicar os textos legais promocionais e programáticos que caracterizam o Estado Social, orientados para a realidade do futuro, às novas e complexas situações da vida real, sobre as quais amiúde as suas intervenções se materializam no mundo sensível, sob a inflexão do regime constitucional (VAZ, 2016, p. 220).

Importante se destacar inclusive que a verificação dos direitos logo no início do processo ganha sua possível efetividade com a obrigatória designação da audiência prévia de conciliação, regulamentada tanto pelo novo Código de Processo Civil quanto pela Lei $n^{0}$ 13.140/2015.

A conciliação pode representar um maior adiantamento temporal, uma nova temporalidade para a fruição dos direitos fundamentais. A possibilidade do exercício desses direitos logo no início do processo, e não só no final, depois de onerosa tramitação, mitiga os entraves temporais intrínsecos ao processo jurisdicional. Resgata, ademais, o senso de responsabilidade e a autonomia das partes em relação à solução do seu conflito, o que poder maximizar a eficácia da decisão e a consequente satisfação em relação ao seu conteúdo. Ao garantir e criar condições para a realização dos direitos sociais em menor tempo, a conciliação contribuiu para a elevação do nível de cidadania dos indivíduos (VAZ, 2016, p. 399).

Dessa forma, é preciso que o princípio da consensualidade seja efetivado mediante a oportunidade de uma solução consensual, seja nos Centros de Conciliação ou nas varas especializadas.

Os meios de resolução de conflitos possibilitam a solução mais célere dos conflitos, como explica Spengler (2016, p. 85), "além disso, se possível o consenso entre os conflitantes (seja pela reconciliação, seja pelo acordo), um processo judicial 
pode ser evitado ocorrendo, aqui sim, a diminuição do contencioso judicial e a celeridade na resposta".

Assim, os mecanismos restaurativos permitem a efetivação de uma gestão local participativa, democrática e descentralizada, baseada nas relações sociais entre a comunidade e o poder público. Além disso, o resultado desta interação mobiliza o capital social e constitui a rede de cooperação, construindo, por conseguinte, uma ação coletiva de redução das desigualdades sociais e de solidificação do sentimento de pertencimento a uma comunidade (SPENGLER; LUCAS, 2011, p. 98).

Dentre os objetivos do Estado de Bem-Estar Social está justamente a igualdade entre os cidadãos. Se, aliado a isso, houver o resgate do sentimento de integrante efetivo da sociedade muito se beneficiará as relações entre o público e o privado.

Nesse sentido, o artigo 175 do novo Código de Processo Civil assim disciplina:

Art. 175. As disposições desta Seção não excluem outras formas de conciliação e mediação extrajudiciais vinculadas a órgãos institucionais ou realizadas por intermédio de profissionais independentes, que poderão ser regulamentadas por lei específica (BRASIL, 2015).

Desse modo, a lei abre possibilidades de regulamentar práticas diferentes de conciliação e de mediação:

Apresenta-se aqui norma em aberto, que permite futuras formas de aplicações dos princípios de mediação e conciliação. Tem-se, por exemplo - e na leitura conjunta com o art. 174 - a possibilidade de implantação desses sistemas já em âmbito administrativo, tratando de forma salutar as demandas do cidadão em relação ao Estado. Estar-seia diante de um grande passo na busca da demonstração - eficiente e comprometida -, do interesse e da boa vontade do Estado, grande "cliente" do Poder Judiciário, demonstrar aquilo que a sociedade tanto vem postulando: disposição para a redução das demandas e, por conseguinte, do tempo de duração e do custo daquelas existentes. $O$ tempo de tramitação das ações, hodiernamente, está diretamente vinculado à quantidade destas; o item está vinculado à existência de demandas muitas vezes desnecessárias; a desnecessidade das ações está, por sua vez, diretamente vinculada à falta de busca de soluções anteriores ao ajuizamento da ação (SPENGLER, 2016, p. 116).

Os meios consensuais de resolução de conflitos revelam possibilidades de redução de ações, de conflitos, e de concretização da pacificação social pela 
Administração Pública. Nessa perspectiva, a análise do caso apresentado é essencial para identificar o tipo de conflito e o melhor mecanismo para a sua resolução. Alguns fatos serão apropriados para a conciliação, outros poderão requerer a interferência dos meios tradicionais do Poder Judiciário, mas a conciliação deve se ter como primeiro mecanismo.

Impõem-se também transformações no âmbito do Poder Público, no concernente à sua práxis administrativa e judicial, compreendendo os seguintes pontos: a) uma viragem hermenêutica administrativa pode contribuir para reduzir o número de demandas que chegam aos juizados federais; b) a possibilidade de conciliação na via administrativa pode ser outro contributo à redução de demandas; c) não sendo factíveis ambas as hipóteses, uma maior adesão aos programas de conciliação judicial poderá representar um encurtamento temporal para o particular aceder ao direito social e também uma economia de trabalho e recursos para o Poder Público, além de desobstruir os canais de acesso à justiça (VAZ, 2016, p. 404).

A utilização dos meios de resolução de conflitos diferentes da forma tradicional pode diminuir o volume de ações repetitivas, oportunizar a economia de recursos públicos, bem como o aprimoramento da eficiência administrativa, pois traz empoderamento do cidadão com sua participação nas decisões. Além disso, oportunizam repensar a burocracia dos órgãos públicos do Estado de Bem-Estar Social na concretização dos direitos fundamentais sociais.

Ademais, no estudo sobre a conciliação em face do Instituto Nacional do Seguro Social, realizado por Foppa e Duque (2017, p. 108), foram entrevistados operadores do direito que atuam na Justiça Federal da Subseção Judiciária de Porto Alegre/RS, oportunidade em que destacam alguns pontos positivos:

Outros aspectos positivos: "a ação é muito rápida e o pagamento sai em poucos meses. A parte pode expor sua situação fática e a sentença é construída pelas partes. A renúncia de $5 \%$ é mínima. Muitos acordos superam inclusive as expectativas de sentença" (GIUSTINA, 2014). A conciliação "atende aos anseios do segurado de forma mais célere e, principalmente, Ihe oportuniza sentir-se partícipe do processo. Na conciliação, o segurado ganha voz, faz uma opção, ainda que restrita, já que do outro lado temos um ente público com limites objetivos para transigir" (LOPES, 2014) (2017, p. 108).

Portanto, percebem-se vantagens advindas da conciliação efetuada em relação 
aos direitos fundamentais sociais pela autonomia criada ao cidadão na decisão sobre seus interesses. Ao verificar que os direitos sociais são essenciais ao ser humano e que o Estado não os está implementando a contento, dando ensejo à judicialização das relações sociais, à luz da cultura do litígio, busca-se, em primeiro lugar, resolver as contendas no Poder Judiciário, razão pela qual é primordial fomentar as mudanças de conduta na resolução e/ou tratamento dos conflitos.

A conciliação foi uma conquista de grande relevância para o desenvolvimento da preservação da garantia constitucional do acesso à Justiça e consolida a ideia de que um acordo bem construído é sempre a melhor solução. E como efeito prático, a conciliação contribui para a Justiça Federal, principalmente no que se refere ao imediato atendimento do jurisdicionado, com a diminuição do acervo processual, com a economia de tempo e com a satisfação do jurisdicionado. A Justiça Federal se beneficia da maior agilidade no trâmite dos processos, pois este é encaminhado para a conciliação e costuma ser resolvido em poucos meses. Assim, não há acúmulo de processos muito antigos. Contudo, não se pode atestar que a conciliação é a melhor opção, até porque nem todos os casos são compatíveis com a conciliação; muitas vezes, a conciliação não é o meio de solução de conflito mais benéfica; tudo dependerá do caso a ser analisado. Mas a conciliação sempre deve ser a primeira alternativa e a mais estimulada como instrumento de grande potencial que é para a pacificação dos conflitos (FOPPA; DUQUE, 2017, p. 119).

Ao se ter um conflito que envolve os órgãos públicos, deve ser realizada uma análise do tipo de conflito e qual meio poderá ser utilizado.

Vale dizer, é necessário um exame sério e abrangente da consistência dos argumentos fáticos e jurídicos invocados por cada cidadão, empresa ou entidade que esteja a questionar um ato do Poder Público ou a pleitear algo em face deste. Algumas vezes, se poderá concluir preliminarmente que não é caso de contestar o pedido, porque assiste razão ao particular, no todo ou em parte. E se a ele assiste razão, a medida mais econômica (porque evita gastos maiores posteriores, inclusive com a utilização da máquina administrativa e/ou jurisdicional) e a única admissível juridicamente para um ente público, vinculado que está ao princípio da legalidade, é atender ao pleito. Não há, nessas hipóteses, espaço para uma negociação propriamente dita, mas sim para o reconhecimento total ou parcial da procedência do pedido. Outras vezes, a conclusão que deflui dessa análise, ainda que preliminar, é de que o pleito do particular não tem fundamento fático e/ou jurídico, de modo que tampouco resta outra alternativa senão contestá-lo, protegendo assim tanto ao interesse público primário, de que as regras 
sejam cumpridas, quanto ao secundário, de que o patrimônio público não seja afetado por pleitos abusivos. Outras tantas vezes, porém, se verificará que existe algum grau de probabilidade de que o particular tenha razão, mas ainda não existe certeza fática (por ser eventualmente necessária a instrução ou as provas já existentes não serem conclusivas) ou jurídica (por serem admitidas diversas interpretações das normas jurídicas aplicáveis e/ou porque a própria jurisprudência está dividida acerca do tema). E aí reside o espaço para a utilização da resolução consensual de conflitos. Quando se verifica a incerteza, devese proceder a uma avaliação de risco, de modo que se verifiquem quais são chances de o particular ter êxito em seu pleito num processo adversarial, à luz das provas e do direito aplicável. Se essas chances forem significativas, valerá a pena buscar uma solução consensual. Para viabilizar a adoção desse caminho, entretanto, é desejável que existam parâmetros prévios estabelecidos em normas legais ou administrativas, que estipulem critérios para a celebração de acordos ou transações, bem como as autoridades encarregadas de realizar a análise de risco e, por fim, de autorizar os acordos em cada caso. Convém que tais decisões sejam tomadas de forma colegiada, com a participação de pessoas ligadas à área jurídica, bem como à área técnica afetada. De outra parte, em consonância com o princípio da isonomia, como já dito, esse colegiado deverá verificar a eventual ocorrência de conflitos repetitivos, de maneira a analisar de forma plena a viabilidade técnica e financeira de cumprir acordos com outros que se encontrem em situação semelhante (por conta do efeito precedente), inclusive, se for o caso, para propor regras para eventuais pagamentos parcelados (SOUZA, 2016, p. 216-217).

Nesse contexto, torna-se necessário realizar uma análise da pretensão do cidadão ou ente privado para identificar as situações em que é possível ou obrigatório transigir. No caso de pedidos realizados administrativamente, o reconhecimento do pedido pela Administração Pública após a transação evita custas processuais e honorários advocatícios, pois não haverá aumento do valor da dívida, com juros e correção, além de aliviar a sobrecarga do Judiciário representada pelas inúmeras ações em que resta vencida a Administração Pública.

Diante da complexidade das relações sociais e políticas e do excesso de demandas judiciais, torna-se essencial a participação do cidadão na gestão dos conflitos, bem como a utilização de meios consensuais como a conciliação para a resolução de divergências envolvendo os direitos sociais. 


\section{CONSIDERAÇÕES FINAIS}

Na medida em que se verifica que os direitos sociais não estão sendo garantidos pelo Estado urge a utilização efetiva de um mecanismo que facilite a aproximação do cidadão com o Estado de modo a facilitar o atendimento dos direitos.

Nesse norte a conciliação se revela não apenas meios de acesso à justiça, mas também mecanismo mais célere e eficaz de acordos entre conflitantes, em especial a partir dos próprios órgãos públicos.

Os direitos sociais fazem parte dos direitos essenciais do ser humano, no entanto, percebe-se que a busca pela garantia desses direitos não precisa refletir em um litígio, cabendo à Administração Pública não protelar essa garantia com ações e recursos judiciais, aumentando o desgaste entre Poder Público e a sociedade. Ao Instituto Nacional do Seguro Social - INSS, por exemplo, não é cabível sonegar direito ou obter desconto nos valores a serem pagos aos beneficiários, sua função é conceder o benefício a quem tem direito.

Ao longo do estudo realizado, foram analisados os casos em que é parte o INSS por ser um dos maiores litigantes judiciais, então, verificando-se algumas características dos Juizados Especiais Federais, por receber demandas sobre a seguridade social e outros direitos sociais, em conflitos que possuem como parte o Poder Público. Nessa seara, foi trazido posicionamento no sentido da aderência à conciliação e não à mediação como meio de resolução desses conflitos. Além disso, foi verificado que têm sido implementadas ações para a conciliação e o fechamento de acordos, no entanto, ainda se tem uma tendência a deixá-las de lado e continuar com o formalismo dos processos adjudicatórios, realidade comprovada pelos números apresentados pelo CNJ, particularmente envolvendo o INSS, campeão em litigância. Independentemente dos meios autocompositivos, que precisam ser utilizados com intensidade, vislumbra-se a necessidade de abertura a processos mais democráticos, tendo por escopo a maior participação do cidadão.

Acerca do princípio da consensualidade, o qual consagra os meios autocompositivos de resolução de conflito e a própria dinâmica da Administração Pública, observou-se que tem encontrado dificuldade de efetivação. É um problema 
entendido como central, pois é perceptível uma grande resistência dos profissionais do direito quanto à ampliação dos procedimentos para oportunizar a solução consensuada, uma não aderência aos meios que a Lei já consagrou como mecanismos. Essa cultura da litigância precisa ser superada, mediante a verificação do papel do Estado, dos Cursos de Direito, dos professores, dos advogados, dos juízes, e de todos os servidores públicos.

A conciliação se revela como grande potencial para diminuir a judicialização das relações, pois uma vez solucionando conflitos em que o Poder Público é parte, consequentemente, o número de ações diminuirá, oportunizando ao Poder Judiciário maior estrutura para julgar os demais casos.

\section{REFERÊNCIAS}

BERWANGER, Jane Lúcia Wilhelm. Fórum institucional previdenciário: espaço privilegiado de construção dialogada da cidadania. In: BERTASO, João Martins; VERONESE, Osmar; PIAIA, Thami Covatti (Org.). Diálogo e Entendimento: direito e multiculturalismo \& políticas de cidadania e resoluções de conflito. Tomo 6. Campinas, SP: Millenium Editora, 2015. p. 251-270.

BRASIL. Constituição da República Federativa do Brasil de 1988. Disponível em: $<$ http://www.planalto.gov.br/ccivil 03/constituicao/ConstituicaoCompilado.htm>. Acesso em: 02 fev. 2017.

Lei $\mathrm{n}^{\circ}$ 9.099, de 26 de setembro de 1995. Dispõe sobre os Juizados Especiais Cíveis e Criminais e dá outras providências. Disponível em: < http://www.planalto.gov.br/ccivil_03/leis/L9099.htm>. Acesso em: 15 out. 2017.

Lei no 10.259, de 12 de julho de 2001. Dispõe sobre a instituição dos Juizados Especiais Cíveis e Criminais no âmbito da Justiça Federal. Disponível em: < http://www.planalto.gov.br/ccivil_03/leis/LEIS_2001/L10259.htm>. Acesso em: 15 out. 2017.

Lei no 8.212, de 24 de julho de 1991. Dispõe sobre a organização da Seguridade Social, institui Plano de Custeio, e dá outras providências. Disponível em: <http://www.planalto.gov.br/ccivil_03/leis/L8212cons.htm>. Acesso em: 15 out. 2017.

. Lei no 8.213, de 24 de julho de 2001. Dispõe sobre os Planos de Benefícios da Previdência Social e dá outras providências. Disponível em: <http://www.planalto.gov.br/ccivil_03/leis/L8213cons.htm>. Acesso em: 15 out. 2017. 
. Decreto no 7.392, de 13 de dezembro de 2010. Aprova a Estrutura Regimental e o Quadro Demonstrativo dos Cargos em Comissão da Advocacia-Geral da União, aprova o Quadro Demonstrativo dos Cargos em Comissão da ProcuradoriaGeral Federal e remaneja cargos em comissão para a Advocacia-Geral da União e para a Procuradoria-Geral Federal. Disponível em: <http://www.planalto.gov.br/ccivil_03/_Ato2007-2010/2010/Decreto/D7392.htm>. Acesso em: 15 out. 2017.

. Portal da Justiça Federal da 4a Região, 2014. Seção Judiciária do Rio Grande do Sul. Disponível em: <https://www2.jfrs.jus.br/instalada-a-primeira-varafederal-de-conciliacao-do-pais/>. Acesso em: 22 nov. 2017.

. Lei $n^{\circ}$ 13.105, de 16 de março de 2015. Código de Processo Civil. Disponível em: <http://www.planalto.gov.br/ccivil 03/ Ato20152018/2015/Lei/L13105.htm>. Acesso em: 02 fev. 2017.

. Lei no 13.140 , de 26 de junho de 2015. Dispõe sobre a mediação entre particulares como meio de solução de controvérsias e sobre a autocomposição de conflitos no âmbito da administração pública; altera a Lei n-9.469, de 10 de julho de 1997, e o Decreto nำ70.235, de 6 de março de 1972; e revoga o $\S 2^{\circ}$ do art. 6음 Lei n-9.469, de 10 de julho de 1997. Disponível em: $<$ http://www.planalto.gov.br/CCIVIL 03/ Ato2015-2018/2015/Lei/L13140.htm>. Acesso em: 02 fev. 2017.

CAPPELLETTI, Mauro; GARTH, Bryant. Acesso à Justiça. Tradução de Ellen Gracie Northfleet. Porto Alegre, Fabris, 1988.

CARVALHO, José Murilo de. Cidadania no Brasil: o longo caminho. Rio de Janeiro: Civilização Brasileira, 2016.

CONSELHO NACIONAL DE JUSTIÇA. Resolução no 125, de 29 de novembro de 2010. Dispõe sobre a Política Judiciária Nacional de tratamento adequado dos conflitos de interesses no âmbito do Poder Judiciário e dá outras providências. Disponível em: $<$ http://www.cnj.jus.br/images/atos normativos/resolucao/resolucao 1252911201011 032016162839.pdf>. Acesso em: 02 out. 2017.

Justiça em números 2017: destaques. Brasília: CNJ, 2017. Disponível em: <http://www.cnj.jus.br/files/conteudo/arquivo/2017/09/e5b5789fe59c137d43506b2e4ec4 ed67.pdf $>$. Acesso em: 19 set. 2017.

. Justiça em números 2017: ano-base 2016. Brasília: CNJ, 2017. Disponível

em:

$<$ http://www.cnj.jus.br/files/conteudo/arquivo/2017/09/904f097f215cf19a2838166729516 b79.pdf>. Acesso em: 14 set. 2017.

DAMATTA, Roberto. O que é o Brasil? Rio de Janeiro: Rocco, 2004. 
FOPPA, Flavia; DUQUE, Marcelo Schenk. A conciliação nos processos em face do INSS como realização de direitos fundamentais: à razoável duração do processo. Revista da Esmafe, 2017.

MORAIS, José Luis Bolzan de; SILVEIRA, Anarita Araújo da. Outras formas de dizer o direito. In: WARAT, Luis Alberto (Org.). Em nome do acordo: a mediação no direito. Argentina: alMed, 1999. p. 68-98.

SARLET, Ingo Wolfgang. A eficácia dos direitos fundamentais: uma teoria geral dos direitos fundamentais na perspectiva constitucional. Porto Alegre: Livraria do Advogado, 2015.

SOUZA, Luciane Moessa de. Meios consensuais de solução de conflitos envolvendo entes públicos: negociação, mediação e conciliação na esfera administrativa e judicial. Belo Horizonte: Fórum, 2012.

. Mediação de conflitos e administração pública. In: HALE, Durval; PINHO, Humberto Dalla Bernardina de; CABRAL, Trícia Navarro Xavier. O marco legal da mediação no Brasil: comentários à Lei oㅜ 13.140, de 26 de junho de 2015. São Paulo: Atlas, 2016. p. 207-228.

SPENGLER, Fabiana Marion. Da jurisdição à mediação: por uma outra cultura no tratamento de conflitos. ljuí: Ed. Unijuí, 2010.

Advogado Editora, 2016.

Mediação de conflitos: da teoria à prática. Porto Alegre: Livraria do

SPENGLER, Fabiana Marion; LUCAS, Doglas Cesar. Justiça restaurativa e mediação: políticas públicas no tratamento dos conflitos sociais. ljuí: Ed. Unijuí, 2011.

STANGHERLIN, Camila Silveira; TABORDA, Alini Bueno dos Santos; GAGLIETTI, Mauro. A política judiciária nacional de tratamento adequado dos conflitos de interesses e os óbices à sua efetiva implementação nos juizados especiais cíveis. In: BERTASO, João Martins; VERONESE, Osmar; PIAIA, Thami Covatti (Org.). Diálogo e Entendimento: direito e multiculturalismo \& políticas de cidadania e resoluções de conflito. Tomo 6. Campinas, SP: Millenium Editora, 2015. p. 139-161.

VAZ, Paulo Afonso Brum. Juizado Especial Federal: contributo para um modelo democrático de justiça conciliativa. Brasília: Conselho da Justiça Federal, Centro de Estudos Judiciários, 2016.

WOLKMER, Antonio Carlos. Crise de representação e cidadania participativa na Constituição brasileira de 1988. In: SARLET, Ingo Wolfgang (Org.). 0 direito público em tempos de crise: estudos em homenagem a Ruy Ruben Ruschel. Porto Alegre: Livraria do Advogado, 1999. p. 39-48. 